\title{
BERGSON E A BUSCA METÓDICA DO PEMPO PERDIDO
}

Izilda JOHANSON ${ }^{1}$

- RESUMO: Tendo como ponto de referência o pensamento de Henri Bergson e, a partir dele, a relação de identidade entre liberdade e criação, ação livre e ação criadora, este trabalho tem como propósito levantar algumas questões relativas à função do método em relação a uma filosofia que encara a arte, o artista e a atividade artística como exemplos de que o conhecimento acerca do real e do verdadeiro é possível e, justamente em virtude disso, os toma como paradigmas da própria filosofia. Em outros termos, interessa aqui dar alguns passos no sentido da investigação acerca do que quer e o que pode uma filosofia que guarda profundas afinidades com a arte e que, além disso, busca entendê-la em sua essência, compreendê-la em seus princípios e revelar a sua natureza.

- PALAVRAS-CHAVE: Bergson; liberdade; criação; método; arte

\section{I}

E bem o que a Natureza fez de vez em quando, por distração, para alguns privilegiados, a Filosofia, em matéria parecida, não poderia tentar, num outro sentido e de uma outra maneira, para todo mundo? O papel da Filosofia não seria aqui o de nos levar para uma percepção mais completa da realidade por um certo deslocamento de nossa atenção? Tratar-se-ia de desviar essa atenção do lado praticamente interessante do Universo e de fazê-la voltar-se àquilo que,

1 Doutoranda do Departamento de Filosofia da Universidade de São Paulo 
praticamente, não serve a nada. Essa conversão da atenção seria a própria Filosofia (Bergson, 1, p.153).

Em La Perception du Changement Bergson afirma que a filosofia compreendida e exercida tal como ele a concebe, isto é, livre e desembaraçada de certas tendências e certos equívocos clássicos - poderá fazer para as pessoas de um modo geral mais ou menos aquilo que a $\mathrm{Na}$ tureza fez para os artistas. E o que a Natureza fez para os artistas? Ela desligou, desvinculou neles o conhecimento real do interesse pela vida. O que significa, em termos mais precisos, que, no artista e em relação às pessoas comuns, os obstáculos para uma percepção mais alargada, mais próxima da temporalidade pura, são mais facilmente transponíveis, devido justamente à sua natureza de artista.

Esse desligamento do conhecimento real do interesse pela vida diz respeito, antes de tudo, a uma espécie de distração, que se dá em relação à tendência natural do ser humano de atenção à vida. O artista, pode-se dizer, é um desatento relativamente à consciência prática e sempre orientada para a ação, que concentra seus esforços naquilo que transforma a todo tempo o presente em futuro e aceita do passado apenas o que pode ajudá-lo a esclarecer o momento que advirá. A atitude do artista, como artista, isto é, desligado em certo grau e em relação a certo sentido da ação prática, segue na direção oposta ao que é habitual para o espírito: ao contrário do que naturalmente requer a consciência, a saber, um máximo de concentração e ao mesmo tempo um mínimo de amplitude, a atitude do distraído, em virtude mesmo de sua distração, chega a alcançar as zonas mais profundas e dilatadas do eu, em que se encontra tudo o que nossa percepção apreendeu do mundo exterior e que, em virtude do processo de "triagem" que o nosso sistema intelectual realiza, lá permanece na forma de esquecimento.

Os hábitos de pensamento e raciocínios aos quais nos impele a vida só fazem sentido se o que estiver em questão for a própria vida comum, isto é, um conhecimento que visa à ação em virtude de uma permanência do ser humano no mundo. Mas se o que está em questão é o conhecimento especulativo, que visa à gênese e a explicação da própria vida e da existência, então o caminho deverá ser o contrário ao habitual, pois a vida em si mesma, o real, a existência real ultrapassa toda e qualquer necessidade e individualidade, e se nós não temos acesso ao que é, é porque nos detemos demais no que funciona. Nesse sentido, o que a nova filosofia poderá e deverá fazer é apontar primeiramente os maus hábitos (com relação ao conhecimento do ser, da existência, da vida) e, 
em seguida, dar as condições para marchar na direção do conhecimento verdadeiro. Conhecimento, no mais, que deverá possibilitar, entre outras coisas, que cada indivíduo possa conhecer o ser a partir de si próprio, que possa conhecer a si próprio, construindo seu próprio percurso "de si para si mesmo". A constituição do método deverá levar o filósofo a percorrer um longo caminho - e mostrar, por exemplo, as confusões e intromissões dos dados espaciais na percepção do tempo, ou a "inutilidade" do conhecimento real em face da "utilidade" do conhecimento abstrato e representacional -, isso para que ele possa fazer algo próximo ao que a Natureza fez num ato simples: dar marcha, ou as condições de se marchar na direção do Tempo Perdido. Podemos dizer que a principal tarefa do filósofo, nesse sentido, deverá ser, ao fim e ao cabo, a de nos livrar dos obstáculos para um conhecimento verdadeiro, sobretudo acerca de nós mesmos, nosso eu integral que é essencialmente memória. Em outras palavras, uma vez que a ação livre pressupõe essa integralidade do eu em plena atividade - e não apenas sua parte mais superficial, que visa a atender às necessidades funcionais -, a filosofia poderá nos dar as condições de avançarmos livremente com nosso ser no mundo. Tal como acontece com o artista, pois de certa maneira essa sua distração é também uma espécie de atalho à ação livre que fortuitamente a Natureza lhe concedeu.

\section{II}

Há identidade entre o que somos e o ato de nossa liberdade, ou melhor, entre esse ato e nós há uma "indefinível semelhança", afirma Bergson nos Ensaios sobre os Dados Imediatos da Consciência, como, por vezes, se encontra entre a obra e o artista. A fim de compreender melhor o sentido preciso dessa afirmação, e da própria noção de liberdade, poderíamos nos perguntar, em primeiro lugar, o que significa essa semelhança entre nosso eu e nossos atos e, no caso da arte, entre a obra e o artista? Nossos atos livres são, em relação a nós mesmos, o resultado de um processo de amadurecimento, o qual não pode ser predeterminado nem desvinculado de nosso eu como um todo. Somente o nosso eu, isto é, tudo que somos e fomos até então é que lhes pode "reivindicar a paternidade". Eles são resultado de um movimento interno criador, e por essa razão mesma, único, pessoal, exclusivo, relativo unicamente àquele que o produziu. Eles são, pois, criação. A criação é o possível, ele 
mesmo apresentando-se como realidade: é "a doação de ser ao que não era e que poderia não vir jamais" (Bergson, 2, p. 52). ${ }^{2}$ No caso da arte, a obra não é extensão do artista, pois é um ser próprio, autônomo, mas que também guarda em si algo de sua própria origem - daí a semelhança. A obra é o "fruto amadurecido" que se desprende do artista, e que será dado a conhecer, como um ser único e autônomo, a posteriori, com o seu "desprendimento". A obra de arte é, nesse sentido, um risco, já que não há como prevê-la; e até mesmo o artista só a conhece plenamente quando ela está pronta. Todo o jogo da criação é interno, e se realiza dentro de um campo de hesitação. A hesitação não é senão esse risco, de lançar-se num movimento que não tem mais razão de seguir nesta ou naquela direção, mas que só será reencontrado depois de realizado. A liberdade é o alcance desse esforço de mudança sem garantias. O ato livre, tal como a obra de arte, é o "fruto amadurecido" que poderia não amadurecer. A criação se dá a partir dessa determinação interna, que atravessa a hesitação e faz com que obra, no caso do artista, e nossos próprios atos, com relação a nós mesmos, nasçam, enfim, de seu próprio devir.

Poderíamos nos perguntar também por que essa semelhança é indefinível. Por que e para quem ela é indefinível? A semelhança entre o artista e sua obra é indefinível para nós que a vemos de fora, isto é, nós, os não-artistas, é que não podemos defini-la? Quanto a este ponto, dado que há exclusividade, parece não haver dúvida de que não há mesmo como apreender exatamente a emoção única vivida pelo artista, donde não haver meios para uma comparação. Mas mesmo em relação ao artista, essa relação não seria indefinível por si mesma ao olhar de si mesmo? De tudo o que podemos apreender das noções bergsonianas envolvidas nessa questão, chegamos ao ponto de que do eu o próprio eu não pode ter definição. Não porque seja mistério, um enigma que a vida não nos possa revelar, mas antes porque é o que não tem proporção nem relação: é a incomensurabilidade e a imprevisibilidade. "Às vezes" há semelhança, nunca saberemos, pois nada pode ser dito nem definido a priori. A obra é, com efeito, o "que se diz depois", tarde demais, já que a referência é o ato que a originou, o movimento contínuo do qual surgiu. Ela nunca dirá tudo, pois não há meios materiais para isso, não há

2 Só o possível é o que existe realmente: o que as coisas são para as pessoas comuns é justamente o que elas não são realmente, isto é, algo determinado, fixo e imobilizado. No plano do real as coisas duram. 
linguagem que possa traduzir a emoção da duração. Assim, também o artista toma conhecimento de sua experiência por intermédio de sua obra, e até mesmo para ele, essa experiência não será de todo revelada.

\section{III}

Ao apresentar o tema da liberdade nesses termos, Bergson toma uma direção totalmente diversa daquela tomada pelos defensores da tese do livre-arbítrio. Diferentemente do que acontece ali, na concepção bergsoniana de liberdade não há lugar para um sujeito atemporal diante de dois pólos de uma escolha predeterminada. Esse esquema, nos alerta o filósofo, é puramente representacional. Nossa atitude - aquela que advém do nosso eu mais profundo, isto é, que advém de uma intimidade própria em que há o menor comprometimento possível com as circunstâncias práticas de atenção à vida - esse ato enfim, se dá no tempo. E o que é o tempo, nos ressalta Bergson, senão aquilo que impede que tudo seja dado de uma só vez? "O tempo deve ser, pois, elaboração" (Bergson, 3 , p. 102). A própria modificação engendra modificação: no caso de um pintor, afirma, seu talento "se forma ou deforma, em todo caso se modifica, sob a influência das próprias obras que produz. Da mesma maneira, continua, cada um de nossos estados, ao mesmo tempo em que sai de nós, modifica nossa pessoa, sendo a forma nova que nós iremos nos dar" (Bergson, 5, p. 7). Todo o nosso eu se modifica a cada ação, e então é um eu todo diferente que age livremente a cada vez.

A liberdade bergsoniana se distancia do esquema clássico de alternativa, em que se supõe o sujeito do livre-arbítrio em face de dois pólos ante os quais ele oscila, e nos oferece um novo esquema, o da alternância, de resto compatível com o absoluto da duração. ${ }^{3} \mathrm{E}$ de que se trata essa alternância? O que o Ensaio nos mostra é que o ser humano é tanto mais livre quanto mais a determinação de seu ato emanar do eu profundo; e tanto menos livre quanto mais o eu superficial dirigir, no campo do automatismo, seus atos. Vemos assim, na prática, uma alternância entre dois momentos: aquele em que nosso eu toma a direção do seu interior e aquele outro em que permanecemos na superfície. Assim, quando

3 Cf. Jean-Luis Chédin. Possibilité e Liberté dans l'Essai - Colóquio de Clemont-Ferrand de 1989. Paris: PUF. 
o eu profundo se cala, permanecemos indiferentes ao plano do tempo perdido (plano da interioridade, da memória integral), e a liberdade não se realiza plenamente; e quando o eu superficial reina, a lei nos é dada do exterior, principalmente pelas necessidades sociais. Quando o eu profundo emerge e se impõe, não há um processo de escolha propriamente dita, nem de dever, mas existe antes uma inversão súbita da relação de forças, normalmente desfavorável à manifestação de diferenças individuais, íntimas. Mas se não há que se falar em escolha nem em decisão, devemos nos perguntar então o que faz com que se realize essa inversão na relação de forças. Somos levados assim a observar o papel singular exercido pelas circunstâncias nessa análise acerca do problema da liberdade. São as circunstâncias excepcionais vividas pelo indivíduo que provocam de alguma maneira o eu profundo, dando-lhe densidade e fazendo com que ele se imponha à sua camada mais superficial. E só mesmo circunstâncias muito especiais são capazes de nos retirar da nossa cômoda posição de superfície. O sujeito atemporal do livre-arbítrio dá lugar assim ao indivíduo, o qual não pode ser um a priori, mas um contemporâneo do ato livre: é a pessoa que encontra a ocasião de se recolher, de contrair todo o seu ser num ponto, em um instante que lhe dará uma direção única.

Seguindo os passos do Ensaio, poderíamos afirmar que a liberdade que ele nos apresenta consiste antes num estado do que numa faculdade. Na verdade, um estado de exceção. O próprio termo faculdade parece já remeter fatalmente ao esquema representacional de um sujeito que pode e deve escolher entre possibilidades preexistentes e por isso mesmo exteriores ao próprio tempo. Entretanto, para que se considere o termo estado, é preciso não perder de vista o seu caráter ativo, pois não se trata aqui de uma referência a uma situação de espera ou de passividade, mas muito ao contrário, trata-se de uma atividade que apenas difere da ação ordinária na medida em que a imprevisibilidade é que dita as leis. Mais uma vez, de maneira muito semelhante à do artista quando cria sua obra. O que é uma obra de arte senão elaboração, fazer, trabalho de construção, objeto palpável? Ora, esse trabalho de construção, de composição, de feitura enfim do objeto também se dá no tempo. Assim sendo, não há como supor algo como uma obra possível, no sentido de preexistente, que anteceda a obra real:

Quando um músico compõe uma sinfonia, sua obra era possível antes de ser real? Sim, se entendermos por isto que não havia obstáculos intransponíveis à sua realização. Mas deste sentido negativo da palavra passamos, sem 
perceber, para um sentido positivo; admitimos que tudo o que se produz podia ser antecipadamente percebido por um espírito suficientemente informado, preexistindo assim, sob forma de idéia, à realização; concepção absurda no caso de uma obra de arte, pois desde o momento em que o músico possui a idéia precisa e completa da sinfonia que ele fará, sua sinfonia está pronta. Nem no pensamento do artista, nem, e com maior razão, em nenhum outro pensamento comparável ao nosso, mesmo impessoal, mesmo virtual, estava a sinfonia na qualidade de possível, antes de ser real (Bergson, 2, p.13).

\section{IV}

Dizer que a liberdade se relaciona a um estado, a um estado de exceção propriamente, significa reconhecer que os momentos de liberdade e de criação são de um modo geral muito raros. Na maioria do tempo permanecemos na superfície do nosso eu. Para o artista nem tanto. E por quê? Porque para ele essas circunstâncias extraordinárias propícias à interiorização do seu eu não são tão extraordinárias assim. Ou melhor, devido justamente a essa sua percepção mais desligada, ele é muito mais permeável à força da ação das coisas e dos seres sobre si. As oportunidades para a criação lhe são, digamos, mais favoráveis, devido justamente a sua própria natureza, a sua percepção mais desimpedida do real. Com relação a esse ponto, a filosofia parece desempenhar um papel muito importante. O que pode o filósofo? Ele pode propiciar em certo sentido e grau essa espécie de abertura às circunstâncias tão características nos artistas. De que maneira? Metodicamente.

O método filosófico visa a um meio de apresentar mais diretamente a verdadeira realidade que é puramente temporal e, portanto, imediata. Mas em Bergson, mesmo o imediato precisa de uma mediação, ao menos no sentido de que é preciso livrar o espírito dos hábitos espacializantes da matéria. A filosofia expõe e se expõe no seu percurso crítico. O filósofo não pode deixar que assistamos ao seu trabalho de filósofo. Nesse sentido, podemos dizer que uma das principais contribuições do seu método seria a de viabilizar para todos, ou qualquer um, as condições fundamentais de caminhada em busca da realidade absoluta, que é pura temporalidade. Não obstante a filosofia vise à Totalidade, o conhecimento do real não exclui a esfera da individualidade. No caso de um indivíduo, ele pode se dar na coincidência de sua consciência com sua duração própria. E como já vimos acima, esse é o momento em que o eu se desloca livremente e recria a si próprio. 
Voltando mais uma vez à aproximação entre o ato livre e a atividade artística - ou o que chamaríamos aqui de dimensão estética da liberdade bergsoniana - não seria lícito pensar na atividade filosófica - cujo principal objetivo deve ser o de "provocar um certo trabalho que tende a entravar, na maior parte dos homens, os hábitos de espíritos mais úteis à vida" (Bergson, 4, p.186) e, assim, dirigir a consciência a uma observação mais desimpedida do real - como uma espécie de estímulo dirigido à distração? Não poderá o filósofo, por meio do método, promover uma certa distração com relação à vida, justamente para que se possa, enfim, percebê-la melhor? E isto também não significaria a promoção dirigida da inversão das forças internas do eu profundo que se realiza fundamentalmente em virtude das circunstâncias? Neste caso, pode-se dizer, o filósofo poderá fazer metodicamente algo próximo ao que a Natureza fez com absoluta simplicidade: transformar pessoas comuns em artistas, em agentes livres, criadoras de si mesmas. No caso da vida de cada pessoa, trata-se principalmente de dar condições para que cada indivíduo crie a si próprio, pelo menos mais freqüentemente, tal como o artista incansável em busca de sua própria perfeição.

JOHANSON, I. Bergson and the search for lost time. Trans/Form/Ação, (São Paulo), v.27 (2), p.21-29, 2004.

- ABSTRACT: Having as point of reference the works of Henri Bergson and, from these, the relationship of the identity between freedom and creation, free action and creative action, the purpose of this paper is to bring to light some questions about the function of method to a philosophy which faces the art, the artist and the artistic activity as examples of which the knowledge of the real and of the true are possible, and for this reason, take it as paradigms of the own philosophy. In other words, it interest to give some steps to the direction of the investigations concerning what want and what can a philosophy which has a profound affinities with art and, beyond this, search to understand it in its essence, in its principles, and reveal its nature.

- KEYWORDS: Bergson, freedom, creation, method, art

\section{Referências bibliográficas}

BERGSON, H., "La perception du changement", in: La Pensée et le Mouvant. Paris: PUF, 1996. Introduction a La Pensée et le Mouvant. Paris: PUF, 1996. 
BERGSON, H., "Le possible et le réel", in La Pensée et le Mouvant, Paris, PUF, 1996.

"Introduction a la métaphysique", in: La Pensée et le Mouvant. Paris: PUF, 1996.

. Evolution Créatrice. Paris: PUF, 1996.

Essai sur le Donée Immediates de la Conscience, in: Oeuvres. Édition du

Centenaire. Paris: PUF.

Les Deux Sources de la Moral et de la Réligion. Paris: PUF, 1997.

Kant, I. Crítica da Faculdade do Juízo. São Paulo: Forense Universitária, 1993. 